\title{
Bioconversion of cassava bagasse and sugarcane bagasse using cheap home-made enzymatic cocktails
}

Gabriela Verónica Díaz ( $\square$ gabrielavdiaz@live.com )

Universidad Nacional de Misiones Facultad de Ciencias Exactas Químicas y Naturales https://orcid.org/0000-0001-7206-0852

\section{Silvana Soledad Sawostjanik Afanasiuk}

National University of Misiones: Universidad Nacional de Misiones

Romina Olga Coniglio

National University of Misiones: Universidad Nacional de Misiones

Juan Ernesto Velázquez

National University of Misiones: Universidad Nacional de Misiones

Pedro Darío Zapata

National University of Misiones: Universidad Nacional de Misiones

Laura Lidia Villalba

National University of Misiones: Universidad Nacional de Misiones

María Isabel Fonseca

National University of Misiones: Universidad Nacional de Misiones

\section{Research Article}

Keywords: agroindustrial wastes, Aspergillus niger, pretreatment, enzymatic hydrolysis, bioethanol simulation, cost-effective process

Posted Date: June 29th, 2021

DOl: https://doi.org/10.21203/rs.3.rs-605152/v1

License: (c) (i) This work is licensed under a Creative Commons Attribution 4.0 International License. Read Full License 
1 Bioconversion of cassava bagasse and sugarcane bagasse using cheap home-made enzymatic cocktails

3 Díaz Gabriela Verónica ${ }^{1,2^{*}}$, Sawostjanik Afanasiuk Silvana Soledad ${ }^{1}$, Coniglio

4 Romina Olga ${ }^{1,2}$, Juan Ernesto Velázquez ${ }^{1,2}$, Zapata Pedro Darío ${ }^{1,2}$, Villalba Laura Lidia $^{1}$, Fonseca María Isabel ${ }^{1,2}$

$6 \quad{ }^{1}$ Laboratorio de Biotecnología Molecular, Instituto de Biotecnología Misiones,

$7 \quad$ Facultad de Ciencias Exactas, Químicas y Naturales, Universidad Nacional de

8 Misiones. Ruta Nacional 12, km 7.5. CP 3304, Posadas, Misiones, Argentina.

9 ${ }^{2}$ CONICET, Buenos Aires, Argentina.

* Correspondence: gabrielavdiaz@live.com 
The agricultural industries generate lignocellulosic wastes that can be modified by

14 fungi to generate high value-added products. The aim of this work was to analyze the

15 efficiency of the bioconversion of sugarcane bagasse and cassava bagasse using two

16 cheap home-made enzymatic cocktails from Aspergillus niger LBM 134 (produced also

17 from agroindustrial wastes) and compare the hydrolysis yield with that obtained from

18 the bioconversion using commercial enzymes. Sugarcane bagasse and cassava bagasse

19 were pretreated with a soft alkaline solution before the hydrolysis carried out with

20 home-made enzymatic cocktails of $A$. niger LBM 134 and with commercial enzymes

21 to compare their performances. Mono and polysaccharides were analyzed before and

22 after the bioconversion of both bagasses as well as their microscopic structure. The

23 maximal yield was the $80 \%$ of total glucans saccharified from cassava bagasse. The

24 bioconversion of both bagasses were better when we used the home-made enzymatic

25 cocktails than commercial enzymes. We obtained high added-value products from

26 agroindustrial wastes, home-made enzymatic cocktails and hydrolysates rich in

27 fermentable sugars. The importance of this work lays in the higher performance of the

28 cheap home-made enzymatic cocktails over the hydrolytic performance of commercial 
29 enzymes due to the cost of producing the home-made enzymatic cocktails were more

30 than 500 times lower than commercial enzymes.

31 Keywords: agroindustrial wastes, Aspergillus niger, pretreatment, enzymatic

32 hydrolysis, bioethanol simulation, cost-effective process

\section{1. Introduction}

34 Biomass is the core of the bioeconomy concept where the efficient and sustainable

35 use of this renewable resource constitutes the basis of bioeconomy development [1]. In

36 this context, biorefineries are a key pillar in the development of a future bioeconomy-

37 based society based on the development of biorefineries to produce biofuels and

38 bioproducts from renewable biomass sources and efficient bioprocesses to achieve

39 sustainable production [1]. Renewable feedstocks can be obtained from primary

40 biomass sources or wastes derived from household, industrial and agricultural activities.

41 Using wastes from agricultural activities adds value to the whole chain and those from

42 worldwide crops are an interesting resource.

43 Cassava (Manihot esculenta Cranz) and sugarcane (Saccharum sp.) are two of the

44 major tropical and subtropical agricultural crops [2]. The root of cassava is processed

45 to isolate the starch or to sell cassava as a pre-cooked meal [3]. The industry of cassava 
46 generates $\mathrm{CB}$ as one of the solid by-products; this waste is a problem due to its high

47 percentage of water, which makes more expensive drying and transporting operations

48 [3]. Sugarcane is used for sugar and bioethanol $1 \mathrm{G}$ production and SCB is one of the

49 by-products of this industry. Both $\mathrm{CB}$ and SCB are generated in large quantities by their

50 respective industries [4]. The improper disposal of these material represents an

51 environmental problem increasing the pollution; however, these agroindustrial wastes

52 can be used for obtaining added-value products while reducing the environmental

53 pollution [5]. The starch, cellulose and hemicelluloses in CB and SCB can be converted

54 into monomeric sugars that can fermented into bioethanol $[6,7]$.

55 The conversion of hemicellulosic biomass to bioethanol involves a pretreatment to

56 open up the biomass structure following by an acid or enzymatic hydrolysis of the

57 complex carbohydrates into simple sugars and their fermentation into ethanol that must

58 be purified for its use as a fuel [5]. The enzymatic hydrolysis has advantages over the

59 acidic hydrolysis, the enzymatic hydrolysis requires less energy and milder

60 environmental conditions and does not require harsh conditions or high temperature

61 and pressure [5, 8]. Moreover, the use of enzymes, i.e., cellulases and hemicellulases is

62 the most promising method for hydrolysis of polysaccharides to monomer sugars due 
63 to hemicellulases facilitate cellulose hydrolysis by exposing the cellulose fibers, thus

64 making them more accessible and promoting the commercial production of

65 lignocellulosic ethanol [9]. However, the cost of enzymes production is one of the most

66 important factors that improve the total costs in the bioethanol production $[10,11]$.

67 Therefore, research have focused on reducing the costs of enzymes by improving the

68 activity of enzymes or by proposing new low-cost enzymatic cocktails that can perform

69 the conversion of polysaccharides to fermentable monosaccharides [12].

70 The current challenge on SCB and $\mathrm{CB}$ hydrolysis consist in using enzymatic

71 cocktails instead of pure commercial enzymes due to many enzymatic classes are

72 required to convert agroindustrial wastes such as SCB and $\mathrm{CB}$ into fermentable sugars

$73[12,13]$. The home-made enzymatic cocktails of $A$. niger LBM 134 grown on SCB and

74 CB were selected to carrying out the hydrolysis of these two agroindustrial wastes. The

75 rationale for using these home-made cocktails was the saccharification potential they

76 presented because the wide spectrum of enzymes they showed [14, 15].

77 In this context, the aims of this work were to analyze the efficiency of the

78 conversion of two agroindustrial wastes, SCB and $\mathrm{CB}$ using two home-made enzymatic

79 cocktails of $A$. niger LBM 134 grown on the respective agroindustrial wastes and to 
80 compare these conversions with that carried out with commercial enzymes.

\section{2. Materials and methods}

\subsection{Fungal material}

The fungus $A$. niger LBM 134 was isolated from rotten wood of Misiones rainforest

84 and deposited in the collection of the Molecular Biotechnology Laboratory (LBM, from

85 Spanish Laboratorio de Biotecnología Molecular), of the Biotechnology Institute

86 Misiones "María Ebe Reca", National University of Misiones. Stock cultures were

87 maintained in $39 \mathrm{~g} \mathrm{~L}^{-1}$ potato dextrose agar medium (PDA) at $28^{\circ} \mathrm{C}$ under static

88 conditions until its mycelial development and conserved at $4{ }^{\circ} \mathrm{C}$.

\subsection{Feedstock preparation and chemical composition analysis}

Two different types of agroindustrial wastes were used: sugarcane bagasse (SCB)

91 and cassava bagasse (CB), both generated by the agroforestry industries of Misiones

92 (Argentina). SCB was sampled from a sugarcane mill at San Javier locality and CB was

93 donated by San Alberto Cooperative in Puerto Rico, Misiones. SCB and CB were dried

94 at $60{ }^{\circ} \mathrm{C}$ overnight, respectively, and milled to produce material retained through a 40-

95 mesh screen.

96 The chemical composition of raw material was determined according to the 
97 laboratory analytical procedure (LAP) and biomass analysis of the National Renewable

98 Energy Laboratory (NREL, https://www.nrel.gov). Carbohydrates were determined by

99 high performance liquid chromatography (HPLC). Concentration of sugars and acetic

100 acid (mg mL $\mathrm{m}^{-1}$ ) was calculated using standard curves of pure compounds (Sigma-

101 Aldrich, USA): glucose, cellobiose, xylose, arabinose and acetic acid. All results are

102 expressed on a dry wood basis (OD).

1032.3 Fungal cultivation and preparation of home-made enzymatic cocktails

104 To obtain the two home-made enzymatic cocktails, A. niger LBM 134 was grown

105 in two optimized media containing SCB and CB as carbon sources and incubated under

106 optimal conditions according to Díaz et al. [4]. Then, the culture broths were

107 centrifuged at $10,000 \mathrm{~g}$ for $20 \mathrm{~min}$ at $4{ }^{\circ} \mathrm{C}$ and clarified and sterilized by Chromafil

108 Xtra PET-20/25 (0.20 $\mu \mathrm{m})$ filters (MachereyNagel; Düren, Germany) to obtain the cell-

109 free enzymatic cocktails and finally concentrated using $3 \mathrm{kDa}$ Amicon Ultra centrifugal

110 filters (Merck KGaA; Darmstadt, Germany) to achieve the enzyme levels for carrying

111 out the hydrolysis assays.

$112 \quad 2.4$ Effect of the bioprocess conditions on enzymatic stability activities

113 The effect of the optimal temperature $\left(30^{\circ} \mathrm{C}\right)$ and $\mathrm{pH}(5.0)$ of the hydrolysis process 
114 was evaluated on the stability of endoxylanase (EX), $\beta$-xylosidase (BXL), filter paper

115 activity (FPase) and $\beta$-glucosidase (BGL) activities in both home-made enzymatic

116 cocktails. For that, the enzymatic cocktails were incubated at $30{ }^{\circ} \mathrm{C}$ and $\mathrm{pH} 5.0$ at

117 different intervals $(6,12,24,48,72$ and 96 h). Residual activity of each enzyme was

118 determined and expressed as a percentage, taking the initial enzymatic activity as $100 \%$.

119 The buffer solution used was 0.05 M sodium acetate buffer for achieving pH 5.0.

\section{$120 \quad 2.5$ Determination of enzyme activities}

121 EX activity was determined according to Bailey [16] and FPase activity, according

122 to Ghose \& Bisaria [17] through the quantification of released reducing sugars using

123 beechwood xylan (Sigma-Aldrich, USA) and Whatman no. 1 filter paper as substrates,

124 respectively. Reducing sugars were measured by 1,3-dinitrosalicylic acid (DNS) assay

125 [18] using xylose and glucose as standard curve for EX and FPU activities, respectively.

126 Absorbance was measured at $540 \mathrm{~nm}$. EX activity was expressed as international units

127 (U), defined as the amount enzyme needed to produce $1 \mu \mathrm{mol}$ of xylose per min at

$12850{ }^{\circ} \mathrm{C}$ while FPase activity was expressed as filter paper unit (FPU), defined as the

129 amount of enzyme releasing $1 \mu \mathrm{mol}$ of reducing sugar from filter paper per min at $50^{\circ} \mathrm{C}$.

130 BGL activity was determined according to Ghose \& Bisaria [17] using $\rho$-nitrophenyl- 
$131 \beta$-D-glucobioside (PNPG) as substrate; and BXL activity was determined according to

132 Ghose and Bisaria [17] using $\rho$-nitrophenyl- $\beta$-D-xylobioside (PNPX) as substrate,

133 through the quantification of $\rho$-nitrophenol method. Absorbance was measured at 410

$134 \mathrm{~nm}$. BGL and BXL activities were expressed as U, defined as the amount of enzyme

135 releasing $1 \mu \mathrm{mol}$ of $\rho$-nitrophenol per min at $50{ }^{\circ} \mathrm{C}$.

$136 \quad 2.6$ Bioconversion of SCB and $C B$

$137 \mathrm{SCB}$ and $\mathrm{CB}$ were pretreated with an alkaline solution of $\mathrm{NaOH} 0.85 \%(\mathrm{w} / \mathrm{v})$ to

138 remove lignin and avoid the holocellulose hydrolysis. For that, $10 \mathrm{~g}$ of bagasse was

139 mixed with $200 \mathrm{~mL}$ of the alkaline solution for a consistence of $5 \%(\mathrm{w} / \mathrm{v})$ at $121{ }^{\circ} \mathrm{C}$

140 during $30 \mathrm{~min}$. Then, the bagasses were washed with water and $0.5 \mathrm{M}$ sodium acetate

141 buffer pH 5.0 at $80 \mathrm{rpm}, 25^{\circ} \mathrm{C}$ for $12 \mathrm{~h}$; bagasses were dried at $45^{\circ} \mathrm{C}$ during $24 \mathrm{~h}$. The

142 enzymatic hydrolysis of both agroindustrial wastes were carried out by the home-made

143 enzymatic cocktails of $A$. niger LBM 134 and by commercial enzymes for comparing

144 their performance. Also, two controls of these enzymatic hydrolysis were carried out:

145 1) incubation of bagasses without enzymes for determining the reducing sugars

146 previous the hydrolysis; 2) incubation of the home-made enzymatic cocktails without

147 the bagasses enzymes for determining the reducing sugars of the cocktails. The home- 
148 made enzymatic cocktail for carrying out the hydrolysis of SCB was obtained from $A$.

149 niger LBM 134 grown on SCB and in the same way, the home-made enzymatic cocktail

150 for the $\mathrm{CB}$ hydrolysis was obtained from the fungus grown on $\mathrm{CB}$. For that, $1 \mathrm{~g}$ of

151 pretreated bagasse was incubated with $25 \mathrm{~mL}$ of reaction solution consisting of $0.05 \mathrm{M}$

152 sodium acetate buffer $\mathrm{pH} 5.0,30{ }^{\circ} \mathrm{C}$ and the corresponding enzymatic cocktail

153 containing (in $\mathrm{Ug}^{-1}$ of biomass): EX 300, FPU 10 and BGL 20. The commercial

154 enzymes used were EX of Xylanase (Sigma-Aldrich, USA) $300 \mathrm{U} \mathrm{g}^{-1}$, FPU of

155 Celluclast (Sigma-Aldrich, USA) $10 \mathrm{U} \mathrm{g}^{-1}$ and BGL of Viscozyme (Sigma-Aldrich,

156 USA) $20 \mathrm{U} \mathrm{g}^{-1}$. All the enzymatic hydrolysis and the control assays were carried out at

$15730{ }^{\circ} \mathrm{C}, \mathrm{pH} 5.0,200 \mathrm{rpm}$ during $24 \mathrm{~h}$ without the addition of any antibiotic for no

158 increasing the cost of the bioprocess. After this period, the assays were vacuum filtered

159 and centrifugated at $12,000 \mathrm{~g}$ during $20 \mathrm{~min}$. The resulting supernatants were used to

160 quantify reducing sugars with the DNS method [18] and to identify and quantify

161 monomeric sugars by HPLC analysis.

162 The values were presented as the means of the triplicates \pm the standard deviation.

$163 \quad 2.7$ Hydrolysis yield

164 Saccharification percentages were calculated using reducing sugars with the 
165 following equation [17]:

$166 \%$ saccharification $=\frac{\text { reducing } \operatorname{sugars}\left(\frac{\mathrm{mg}}{\mathrm{ml}}\right) * 0.9 * 100}{[S]\left(\frac{\mathrm{mg}}{\mathrm{ml}}\right)}$

167 where, $[\mathrm{S}]$ is substrate concentration.

168 While saccharification percentage may be an acceptable measure of the rate of

169 enzyme activity for calculations of enzymatic synergy, it does not indicate whether

170 monomer sugars suitable for bioethanol production are present [19]. For that,

171 hydrolysis percentages were determined based on the monomer sugars released after

172 the hydrolysis of bagasses using the following equation proposed by the NREL:

$173 \quad \%$ Hydrolysis $=\frac{\text { glucose cellobiose or } x y l o s e\left(\frac{m g}{m l}\right) * 100}{\text { polysaccharides in the substrate } * F C}$

174 where, FC corresponds to the conversion factor, that is 1.11 for glucose, 1.05 for

175 cellobiose, and 1.13 for xylose.

2.8 Electron microscopic structure of SCB and CB before and after the hydrolysis

Bagasses were observed by scanning electron microscopy (SEM) to evaluate the

178 changes in their microscopic structure during each step of the bioprocess: before and

179 after of the alkaline pretreatment and after the hydrolysis with the home-made

180 enzymatic cocktails and with the commercial enzymes. For that, $0.01 \mathrm{~g}$ of bagasses

181 were fixed in each evaluated step with formaldehyde:alcohol:acid (FAA, 10:50:5). 
182 Then, the samples were dehydrated with increasing concentrations of acetone solutions

183 and dried by the method of critical point with $\mathrm{CO}_{2}$. Finally, the samples were metalized

184 with gold and observed with a scanner electron microscope (JEOL 5800LV).

185

2.9 Simulation model for bioethanol production from SCB and CB

186 Key parameters such as yield coefficients and rate constants used in the generic

187 flowsheet were assessed, based on experimental and theorical data. To establish a

188 simulation model for potential yield of bioethanol production from a combined

189 fermentation of glucose and xylose, experimental concentrations of these sugars

190 reported by Kamoldeen et al. [20] were used (Supplementary table 1).

191 The apparent reaction rate constants for each component were obtained using the

192 experimental concentration values of the components in a progressive reaction. A first

193 order reaction model for glucose and xylose decomposition and conversion rates were

194 proposed. These models were validated with experimental data from the work of

195 Kamoldeen et al. [20]. These models were used to stablish a simulation process of

196 bioethanol production.

2.10 Statistical analysis

198 The experimental and theorical results were analyzed and graphed with the software 


\section{Results and discussion}

\subsection{Characterization of $S C B$ and $C B$}

202

The bioprocesses carried out in this study as a strategy to convert both SCB and CB

203 into enzymatic cocktails and fermentable sugars offered the possibility of obtaining

204 these high added-value products from agroindustrial wastes. Firstly, to know the

205 chemical composition of both SCB and CB for comparing then with monomeric sugars

206 after the enzymatic hydrolysis, the main components of the raw bagasses were

207 identified according to NREL analytical procedure (Table 1). SCB presented more

208 quantities of extractives (fat, proteins, wax), hemicelluloses and lignin than CB.

209 Conversely, CB had more glucans than SCB.

2113.2 Characterization of the home-made enzymatic cocktails of A. niger LBM 134

212 The $\mathrm{pH}$ and thermostability of the key enzymes involved in the hydrolysis of

213 lignocellulosic biomass was studied (FPase, BGL, EX and BXL) in the home-made

214 enzymatic cocktails of $A$. niger LBM 134 due to the $\mathrm{pH}$ and the temperature are two

215 main factors affecting the stability of the enzyme activity. The enzymes of both home- 
made cocktails showed considerable stability, making them promising to be used in the

217 bioconversion of SCB and CB.

218 The polysaccharide hydrolytic activities, FPU, BGL, EX and BXL, of the home-

219 made enzymatic cocktails of $A$. niger LBM 134 were measured (Table 2) and the

220 enzymatic levels demonstrated that these cocktails were suitable for carrying out the

221 bioconversion of SCB and $\mathrm{CB}$. Also, the effect of temperature $\left(30^{\circ} \mathrm{C}\right)$ and $\mathrm{pH}(5.0)$ on

222 the stability of the enzyme activities were studied due to the importance of the

223 enzymatic stability of in any bioprocess (Figure 1). Thermostability of enzymes was

224 above $50 \%$ after $24 \mathrm{~h}$ (Figure 1a-b) and pH stability was above 50\% after $24 \mathrm{~h}$ (Figure

225 1c-d). Therefore, the hydrolysis assays were carried out under these conditions: $30{ }^{\circ} \mathrm{C}$

226 and $\mathrm{pH} 5.0$ for $24 \mathrm{~h}$.

TABLE 2

228

FIGURE 1

2293.3 Bioconversion of SCB and CB

230 Also, raw materials, SCB and CB, were extensively characterized hence the correct

231 choice of any pretreatment strategy depends on knowing the fundamental biochemistry

232 of the biomass and the desired products [21]. For that reasons, we employed a soft 
233 alkaline pretreatment on SCB and CB guarantying a specific lignin removal and

234 preserving the polysaccharides into the sold fraction, a fundamental feature required

235 for the hydrolysis [22].

236 In addition to this effective pretreatment, we used the crude (home-made)

237 enzymatic cocktails of $A$. niger LBM 134 instead of purified enzymes because there are

238 clear indications that proteins with still unknown functions (present in the crude

239 cocktails) may contribute to the hydrolysis of cellulose and hemicelluloses [19, 23].

240 Furthermore, the advantages of applying the home-made enzymatic cocktails of $A$.

241 niger LBM 134 without purification step implies a reduction in the costs of the global

242 biotechnological application. In addition, the home-made enzymatic cocktail of $A$.

243 niger LBM 134 grown on SCB showed high levels of hemicellulases and cellulases and

244 the enzymatic cocktail of the fungus grown on CB presented high levels of starch-

245 degrading enzymes [4]. Therefore, these enzymatic cocktails were used for carrying out

246 the bioconversion of SCB and CB. Both wastes are complex biomass; hence, their

247 bioconversion require more than one or few enzymes. In this context, the co-action of

248 different enzymatic activities of the home-made cocktails of $A$. niger LBM 134 makes

249 the difference compared to the commercial enzymes that present only a few enzymatic 
activities.

251 A soft alkaline pretreatment was applied on SCB and CB to remove the lignin

252 content and make available the polysaccharides of the cell walls. This treatment was

253 efficient to carry out the removal of the lignin content without affecting the

254 carbohydrate fraction (no polysaccharides were detected in this fraction by DNS

255 method). After the pretreatment, a liquid with lignin and a solid fraction with the

256 carbohydrates were formed. The lignin was removed and discarded with the liquid

257 fraction $88.39 \pm 5.83 \%$ for $\mathrm{SCB}$ and $73.20 \pm 0.23 \%$ for $\mathrm{CB}$, from the total lignin content.

258 The lignin removed was also evidenced by the change of colour of the solid fraction;

259 SCB and CB were initially brown before the alkaline treatment and after that, SCB

260 changed to light brown and $\mathrm{CB}$, to yellow cream (data not shown). In addition, there

261 was no polysaccharides loss after the pretreatment of both bagasses due to there were

262 no sugars detected in the liquid fraction by the DNS assay.

263 The enzymatic hydrolysis of the pretreated bagasses was carried out with the home-

264 made enzymatic cocktails of $A$. niger LBM 134. The reducing and monomeric sugars

265 from both hydrolysates and controls were shown in Table 3 . The main products of the

266 hydrolysis of SCB were in $\left(\mathrm{mg} \mathrm{mL}^{-1}\right) 4.51 \pm 1.14$ glucose and $3.66 \pm 1.06$ xylose, 
267 achieving a $28 \%$ of conversion to glucose and $42 \%$ to xylose, respectively. These

268 conversion percentages were similar to that obtained from the hydrolysis of pretreated

269 SCB using commercial enzymes: $23 \%$ conversion to glucose and $42 \%$ to xylose. The

270 hydrolysates from $\mathrm{CB}$ were rich in glucose, $5.12 \pm 0.89 \mathrm{mg} \mathrm{mL}^{-1}$; reaching a $16.5 \%$ of

271 conversion, three times higher than that obtained using commercial enzymes. Reducing

272 sugars were also determined to estimate the saccharification yield; hydrolyzed

273 pretreated CB with the home-made enzymatic cocktails of A. niger LBM 134 showed

274 the maximal saccharification yield, $80 \%$.

277 Electronic microscopic photographs were taken of typical features of both bagasses

278 before any treatment; the SCB fibers were covered by lignin material (Figure 2a) and

279 the $\mathrm{CB}$ surface was heterogenous and porous (Figure 2b). After the alkaline

280 pretreatment, the parenchyma and conductive vessels of the SCB were altered and the

281 fibers had less cohesion due to the lignin removal (Figure 2c). On the other side, starch

282 granules could be distinguished in the pretreated CB (Figure 2d). Both bagasses were

283 also microphotographed after the hydrolysis. After the hydrolysis of SCB with the 
285 showing a large area exposed to the enzymatic action (Figure 2e). Regarding CB

286 hydrolysis by the enzymatic cocktails of $A$. niger LBM 134, the surface was 287 homogenous and no starch granules were shown (Figure 2f). Cellulose fibers of SCB 288 hydrolyzed by commercial enzymes showed similar changes as SCB hydrolyzed by the 289 enzymatic cocktails of $A$. niger LBM 134 (Figure 2g). CB hydrolyzed by commercial 290 enzymes showed a heterogeneous surface and the presence of starch granules (Figure $2912 h)$.

293 xylanases is at least almost $\$ 900$, more than 500 times the cost of producing the home294 made enzymatic cocktails by $A$. niger LBM 134, $\$ 1.90$ and $\$ 1.65$ when the fungus grew 295 with SCB and CB, respectively. FIGURE 2 diagram contemplates feedstock preparation (Figure 3a) and their main component proportions; the enzymes production using the bagasses as carbon sources and the 
301 fungus $A$. niger LBM 134 (Figure 3b) until the obtention of ethanol by a simulation 302 model.

303 Glucose and xylose yields were used to simulate the fermentation and obtention of

304 bioethanol curve-fitting model (Figure 3d). Firstly, the experimental concentrations of

305 a glucose-xylose combined fermentation reported by Kamoldeen et al. [20] were used 306 for simulating the bioethanol production model (Supplementary table 1). For a more 307 complete utilization of all fermentable sugars released in the SCB hydrolysates, the 308 yeast Saccharomyces cerevisiae could be used in addition to pentose-fermenting yeasts 309 like Scheffersomyces stipitis ATCC 5837 as indicated Kamoldeen et al. [20].

310 To obtain the apparent reaction rate constants for each component, the traditional

311 fermentation models were simplified as follows: glucose $>$ ethanol $+\mathrm{CO}_{2} \times 2$ and 3

312 xylose $>$ ethanol $+\mathrm{CO}_{2} \times 5$. Also, the experimental concentrations of glucose, xylose

313 and ethanol from Kamoldeen et al. [20] work were expressed in $\mathrm{mol} \mathrm{L}^{-1}$ in a progressive

314 reaction and a first order reaction model was suggested for glucose and xylose

315 decomposition rates:

$316-\operatorname{Ln}\left(\frac{C_{G}}{C_{G 0}}\right)=k_{G} t ;-\operatorname{Ln}\left(\frac{C_{X}}{C_{X 0}}\right)=k_{X} t$

317 Experimental data from Kamoldeen et al. [20] work were adjusted to both 
318 logarithmic expressions and $k_{G}$ and $k_{X}$ constants were obtained, $k_{G}=0.2631$ and $k_{X}=$

3190.0754 , considering the time lag between glucose and xylose consumption start. The

320 conversion models for glucose and xylose were as follows:

$321 C_{G}=C_{G 0} e^{-0,2631 t} ; C_{x}=C_{x 0} e^{-0,0754 t}$

322 where, $\mathrm{G}$ is glucose; $\mathrm{X}$ is xylose; $\mathrm{t}$ is time. These models were validated with

323 experimental data and no statistical difference was found for $\mathrm{P}<0.05$ (Supplementary

324 Table 2). The validated conversion models and the $k_{G}$ and $k_{X}$ constants were used to

325 established the bioethanol production models (Supplementary Table 3):

326

$C_{E G}=2 C_{G 0}\left[1-e^{(-0,2631 t)}\right] ; C_{E X}=5 / 3 C_{X 0}\left[1-e^{(-0,0754 t)}\right]$

327 where, $E G$ is ethanol production from glucose; $G 0$, glucose concentration at time $0 ; E X$,

328 ethanol production from xylose; $X 0$, xylose concentration at time $0 ; \mathrm{t}$, time.

329

The validation of the models was carried out applying them to experimental and

330 theorical data and comparing with the experimentally produced bioethanol. The model

331 fitted well with the experimental data, there was no significance difference for $\mathrm{P}<0.05$

332 (Supplementary Table 4). Once the ethanol production model was validated, the curve-

333 fitting was employed for simulating the bioethanol yield from experimental data of the

334 saccharification of $\mathrm{SCB}$ and $\mathrm{CB}$, achieving $4.16 \mathrm{mg} \mathrm{mL}^{-1}$ and $2.57 \mathrm{mg} \mathrm{mL}-1$, 

enzymatic cocktails were produced using the respective bagasse as substrate for the

341 that can negatively influence on the fermenting microorganism [10].

343 metabolization of hexoses such as glucose and pentoses as xylose for a more complete

344 utilization of all the sugars released during the hydrolysis of SCB [10]. On the other

345 hand, the fermentation of the hydrolysates of CB was simulated only using the glucose-

346 metabolizing yeast, S. cerevisiae because CB hydrolysates were mainly rich in glucose.

347 From the bioethanol model simulation, the SCB hydrolysates would reach a higher

348 bioethanol yield than the CB hydrolysates; this behavior can be explained by xylose

349 sugars present in the SCB hydrolysates. The importance of the xylose as a fermentable

350 sugar for obtaining bioethanol in higher quantities is relevant since it has been identified

351 that non or poor utilization of the xylose components of biomass is a principal factor 
generally affecting the efficiency of lignocellulosic substrates as a renewable feedstock

353 for bioethanol generation [20].

354 Although the bioconversion of both bagasses reached low values comparing with

355 another works such as Fockink et al. [24] who yielded higher sugars values, the

356 importance of this work is that the performance of the cheap home-made enzymatic

357 cocktails of $A$. niger LBM 134 (produced from agroindustrial wastes) was higher than

358 the hydrolytic performance of commercial enzymes. The conversion to glucose of

359 pretreated SCB confirmed the good performance of cellulases, particularly BGL. This

360 is a very interesting finding due to numerous studies have described a limited

361 production of BGL for almost filamentous fungi including Trichoderma reesei, a well-

362 known cellulase-producer, which cocktails must be added with exogenous BGL [8].

363 Regarding the hydrolysis of SCB with commercial enzymes, the conversion to

364 glucose and xylose were similar to that obtained with the home-made enzymatic

365 cocktails of $A$. niger LBM 134. That fact evidenced the good performance of the home-

366 made enzymatic cocktails used in this work.

367 The bioconversion from glucans to glucoses in CB using the home-made enzymatic

368 cocktails was three times higher than that obtained using commercial enzymes. This 
369 behavior could be attributed to the action of amylases present in the home-made

370 enzymatic cocktails of $A$. niger LBM 134 [15]. The conversion in reducing sugars of

371 CB using the home-made enzymatic cocktail was two times higher than that obtained

372 by [25] hydrolyzing CB with Rhizopus oligosporus (CCT 3762). Moreover, the results

373 in this work are similar to the maximal saccharification percentage obtained by Bayitse

374 et al. [2] hydrolyzing cassava peel with commercial enzymes. In this sense, it is

375 important to highlight that this bioconversion was carried out by home-made enzymatic

376 cocktails and no commercial enzymes. This fact translates into the reduction of costs

377 by using home-made enzymatic cocktails produced from a fungus grown on wastes

378 (SCB and $\mathrm{CB}$ ). Also, we must set up the potential of $\mathrm{CB}$ in order to generate other

379 added-value products, a field poorly explored [25]. The use of this waste as biomass in

380 a biorefinery concept will contribute in countries on process of development and will

381 have a great social and economic impact at regional level through maximizing this local

382 resource to promote industry development and added-value product generation $[1,26]$.

383

384 4. Conclusions

385 The method proposed in this article links the use of predictive model of ethanol

386 yield to conventional biochemical techniques. The complete bioconversion of SCB 
and $\mathrm{CB}$ to bioethanol involved complex steps to transform the carbohydrate polymers into fermentable sugars. One of the main bottlenecks of the bioethanol process is the cost of producing enzymes to be used in the hydrolysis. Therefore, we used home-made enzymatic cocktails from a native fungus, A. niger LBM 134 grown on agroindustrial wastes, SCB and $\mathrm{CB}$. We characterized and analyzed the cost of the home-made enzymatic cocktails we produced and compare the cost with two commercial cellulolytic enzyme mixtures and a commercial xylanase enzyme. We concluded that the bioconversion of SCB and $\mathrm{CB}$ carried out in this work by the home-made enzymatic cocktails of $A$. niger LBM 134 was better than the hydrolytic performance using commercial enzymes and thus converting this bioprocess in a cost-effective strategy. Also, we obtained two added-value products from non-use agroindustrial wastes: enzymatic cocktails and fermentable hydrolysates. For these reasons, we believe that this process can potentially applied and adopted on sugarcane mills and starch industry. 
404 All data generated or analyzed during this study are available in this study.

405 Competing interests

406 The authors declare they have no competing interests.

407 Funding

408 This work was supported by Forest Competitiveness and Sustainability Program of the

409 Ministry of Agriculture, Livestock and Fishing (Argentina) [PIA-14005, FONCYT

410 PICT 2016-4695, 2016].

\section{Authors' contributions}

412 GVD and SSSA conceived the present idea, participated in performing experiments,

413 statistical analysis and the design of figures; in addition, GVD designed the study and

414 wrote the manuscript; ROC participated in performing experiments; JEV analysed

415 part of the results; MIF supervised the project and participated in critical revision of

416 the manuscript and PDZ and LLV supervised the project, contributed reagents and

417 materials and participated in critical revision of the manuscript. All authors read,

418 provided critical feedback, and approved the final manuscript.

\section{Acknowledgements}

420 Not applicable 


\section{Authors' information (optional)}

422

Not applicable

423

424

\section{References}

425 1. H. Mamane, S. Altshuler, E. Sterenzon, and V. K. Vadivel, "ISSN 2300-5599 no. http://www.proakademia.eu/gfx/proakademia2014/userfiles/_public/acta_innov ations/wydanie_37/2020.37.pdf\#page=36.

2. R. Bayitse, X. Hou, A. B. Bjerre, and F. K. Saalia, "Optimisation of enzymatic hydrolysis of cassava peel to produce fermentable sugars," AMB Express, vol. 5, no. 1,2015 , doi: 10.1186/s13568-015-0146-z. characterization of cellulose nanofibers from cassava root bagasse and peelings," Carbohydr. Polym., vol. 157, pp. 962-970, 2017, doi: 10.1016/j.carbpol.2016.10.048. 

doi: 10.1080/00275514.2018.1556557.

440 5. N. A. Edama, A. Sulaiman, and S. N. Siti, "Enzymatic saccharification of Tapioca processing wastes into biosugars through immobilization technology," Biofuel Res. J., vol. 1, no. 1, pp. 2-6, 2014, doi: 10.18331/BRJ2015.1.1.3. cassava-based industrial wastes: Current status and opportunities," Bioresour. Technol., vol. 215, pp. 50-62, 2016, doi: 10.1016/j.biortech.2016.04.026. biomass feedstocks for second-generation bioethanol production: concepts and recent developments," 3 Biotech, vol. 5, no. 4, pp. 337-353, 2015, doi: 10.1007/s13205-014-0246-5. cocktails for lignocellulose breakdown," J. Appl. Microbiol., vol. 125, no. 3, pp. 632-645, 2018, doi: 10.1111/jam.13923. 
10. C. A. Cardona Alzate and O. J. Sánchez Toro, "Energy consumption analysis of integrated flowsheets for production of fuel ethanol from lignocellulosic biomass," Energy, vol. 31, no. 13, pp. 2447-2459, 2006, doi: 10.1016/j.energy.2005.10.020.

11. R. O. Coniglio et al., "Enzymatic hydrolysis of barley straw for biofuel industry using a novel strain of Trametes villosa from Paranaense rainforest," Prep. Biochem. Biotechnol., vol. 50, no. 8, pp. 753-762, 2020, doi: 10.1080/10826068.2020.1734941.

12. G. V. Díaz, P. D. Zapata, L. L. Villalba, and M. I. Fonseca, "Evaluation of new xylanolytic-producing isolates of Aspergillus from Misiones subtropical rainforest using sugarcane bagasse," Arab J. Basic Appl. Sci., vol. 26, no. 1, pp. 292-301, 2019, doi: 10.1080/25765299.2019.1622922.

468 13. B. C. Bussamra, S. Freitas, and A. C. da Costa, "Improvement on sugar cane 469 bagasse hydrolysis using enzymatic mixture designed cocktail," Bioresour. Technol., vol. 187, pp. 173-181, 2015, doi: 10.1016/j.biortech.2015.03.117.

471 14. G. V. Díaz, R. O. Coniglio, C. I. Chungara, P. D. Zapata, L. L. Villalba, and M. 

potential cellulolytic ability," Mycology, vol. 00, no. 00, pp. 1-14, 2020, doi: 10.1080/21501203.2020.1823509.

475

15. G. V. Díaz, R. O. Coniglio, A. E. Alvarenga, P. D. Zapata, L. L. Villalba, and M. I. Fonseca, "Secretomic analysis of cheap enzymatic cocktails of Aspergillus niger LBM 134 grown on cassava bagasse and sugarcane bagasse," Mycologia, vol. 112, no. 4, pp. 663-676, 2020, doi: 10.1080/00275514.2020.1763707.

16. M. J. Bailey, P. Biely, and K. Poutanen, "Interlaboratory testing of methods for assay of xylanase activity," J. Biotechnol., vol. 23, no. 3, pp. 257-270, 1992, doi: 10.1016/0168-1656(92)90074-J.

17. T. Ghose and V. S. Bisaria, "International Union of Pure Commission on Biotechnology * Measurement of," Pure Appl. Chem., vol. 59, no. 2, pp. 257268, 1987, doi: 10.1351/pac198759020257.

18. G. L. Miller, “Use of DinitrosaIicylic Acid Reagent miller1959.”.

19. J. S. Van Dyk and B. I. Pletschke, “A review of lignocellulose bioconversion using enzymatic hydrolysis and synergistic cooperation between enzymesFactors affecting enzymes, conversion and synergy," Biotechnol. Adv., vol. 30, 

no. 6, pp. 1458-1480, 2012, doi: 10.1016/j.biotechadv.2012.03.002.

490

494

495

496

20. A. A. Kamoldeen, C. K. Lee, W. N. Wan Abdullah, and C. P. Leh, "Enhanced ethanol production from mild alkali-treated oil-palm empty fruit bunches via cofermentation of glucose and xylose," Renew. Energy, vol. 107, pp. 113-123, 2017, doi: 10.1016/j.renene.2017.01.039.

21. F. D. Ramos and M. A. Villar, “¿Qué son los biocombustibles y qué lugar ocupan en el panorama energético argentino y mundial?," Univ. Nac. del Sur-Conicet, vol. 25, pp. 69-73, 2016, [Online]. Available: http://ri.conicet.gov.ar/bitstream/handle/11336/25791/CONICET_Digital_Nro. cf291889-a370-4b7a-915b-4de3e1058c97_A.pdf?sequence=2\&isAllowed=y.

22. D. Muñoz Muñoz, A. Pantoja Matta, and M. Cuatin Guarin, "Aprovechamiento de residuos agroindustriales como biocombustible y biorefinería," Ingresar a La Rev., vol. 12, no. 2, pp. 10-19, 2014.

23. R. O. Coniglio et al., "Optimization of cellobiohydrolase production and secretome analysis of Trametes villosa LBM 033 suitable for lignocellulosic bioconversion," Arab J. Basic Appl. Sci., vol. 26, no. 1, pp. 182-192, 2019, doi: 10.1080/25765299.2019.1598107. 

the high-pressure $\mathrm{CO} 2$ pre-treatment of sugarcane bagasse for a delivery of upgradable sugars," Energy, vol. 151, pp. 536-544, 2018, doi: 10.1016/j.energy.2018.03.085.

25. B. Escaramboni, E. G. Fernández Núñez, A. F. A. Carvalho, and P. de Oliva Neto, "Ethanol biosynthesis by fast hydrolysis of cassava bagasse using fungal amylases produced in optimized conditions," Ind. Crops Prod., vol. 112, no. November 2017, pp. 368-377, 2018, doi: 10.1016/j.indcrop.2017.12.004.

514 26. D. Caccia, M. Dugo, M. Callari, and I. Bongarzone, "Bioinformatics tools for secretome analysis," Biochim. Biophys. Acta - Proteins Proteomics, vol. 1834, no. 11, pp. 2442-2453, 2013, doi: 10.1016/j.bbapap.2013.01.039.

518 Table 1 Chemical composition of raw CB and SCB used for the bioconversion. The

519 values represent the means of the triplicates \pm standard deviation.

\begin{tabular}{lcc}
\hline Components & \multicolumn{2}{c}{ Composition (\%) } \\
& \multicolumn{1}{c}{ CB } & SCB \\
\hline Glucans & $72.5 \pm 0.59$ & $43.72 \pm 0.77$ \\
Hemicellulose & $16.6 \pm 1.66$ & $24.99 \pm 8.56$ \\
Soluble lignin & $6.04 \pm 0.15$ & $16.49 \pm 2.55$ \\
Insoluble lignin & $3.29 \pm 0.9$ & $9.37 \pm 1.33$ \\
\hline
\end{tabular}




\begin{tabular}{lll}
\hline Ash & $0.67 \pm 0.06$ & $1.9 \pm 0.4$ \\
Extractives & $1.8 \pm 0.05$ & $4.7 \pm 0.08$ \\
\hline
\end{tabular}

aAnalyzed sugars: xylose, arabinose

523 Table 2 Enzyme activities of home-made cocktails of $A$. niger LBM 134 grown on SCB

524 and CB. Activity levels represented by the means of biological triplicates \pm standard

525 deviation. The cocktails of the fungus grown on SCB and CB contained total proteins

$526 \quad 100.46 \pm 27.01 \mu \mathrm{g} \mathrm{mL}^{-1}$ and $329.62 \pm 1.17 \mu \mathrm{g} \mathrm{mL}^{-1}$, respectively.

\begin{tabular}{lcc}
\hline & \multicolumn{2}{c}{ Crude enzymatic extracts } \\
Enzyme activities $\left(\mathrm{UmL}^{-1}\right)$ & $\mathrm{SCB}$ & $\mathrm{CB}$ \\
\hline Filter paper activity & $0.35 \pm 0.00 \mathrm{UmL}^{-1}$ & $0.38 \pm 0.00 \mathrm{UmL}^{-1}$ \\
& $0.17 \pm 0.00 \mathrm{UmL}^{-1}$ & $0.28 \pm 0.00 \mathrm{UmL}^{-1}$ \\
B-glucosidase & $106 \pm 14.67 \mathrm{UmL}^{-1}$ & $144 \pm 5.65 \mathrm{UmL}^{-1}$ \\
Endoxylanase & & \\
B-xylosidase & $0.74 \pm 0.05 \mathrm{UmL}^{-1}$ & $0.18 \pm 0.03 \mathrm{UmL}^{-1}$ \\
\hline
\end{tabular}

529 Table 3 Released sugars from the enzymatic hydrolysis of SCB and CB. In this

530 bioconversion, we used the home-made cocktails of $A$. niger LBM 134 and controls.

531 The values represent the means (in $\mathrm{mg} \mathrm{mL}^{-1}$ ) of the biological triplicates \pm standard 532 deviation.

\begin{tabular}{|c|c|c|c|c|c|c|}
\hline Assays & $\begin{array}{c}\text { Reducing } \\
\text { sugars }\end{array}$ & Cellobiose & Glucose & Xylose & Arabinose & $\begin{array}{c}\text { Acetic } \\
\text { acid }\end{array}$ \\
\hline \multicolumn{7}{|c|}{ SCB } \\
\hline
\end{tabular}




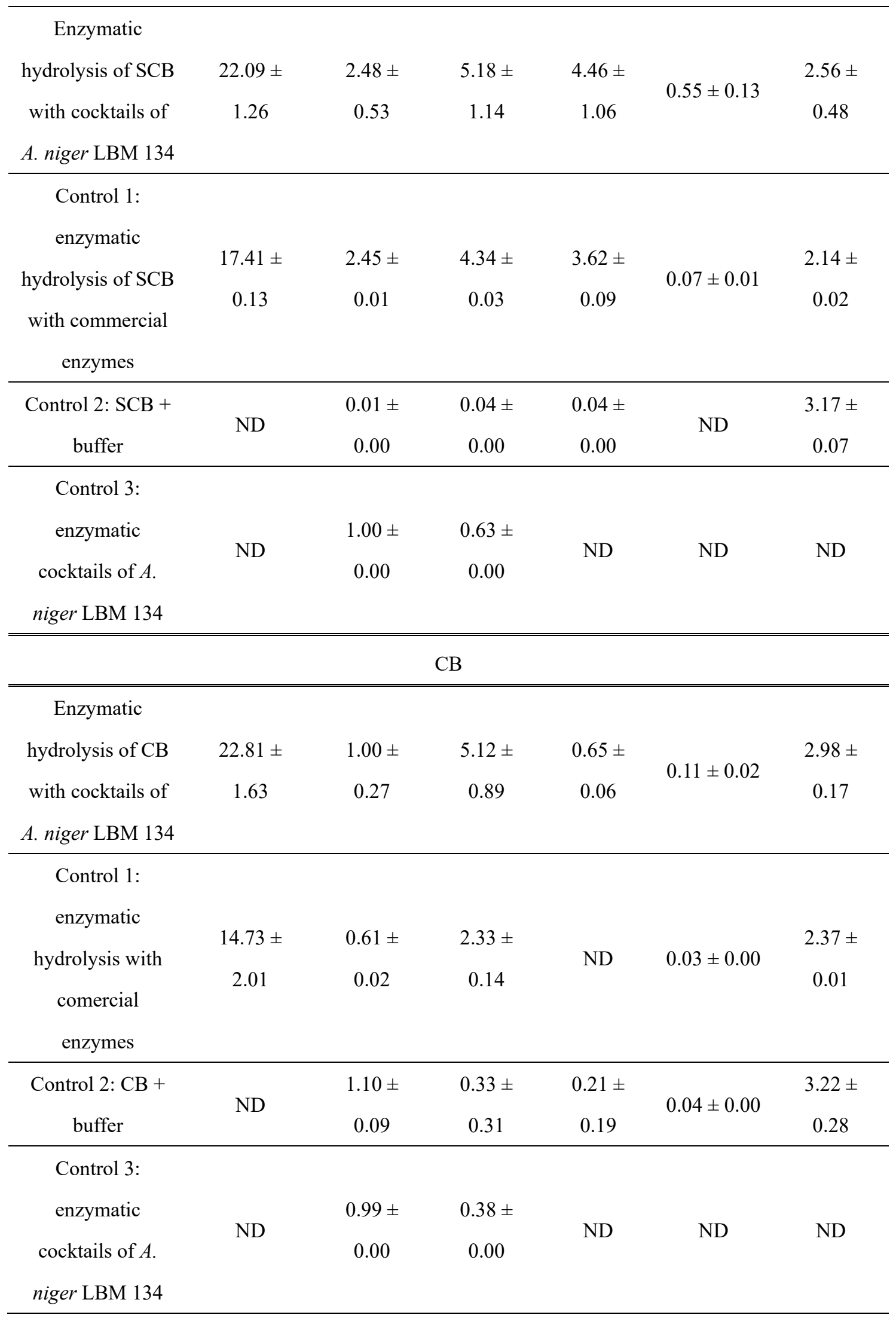

534 ND: not detected 


\section{$536 \quad$ Figure}
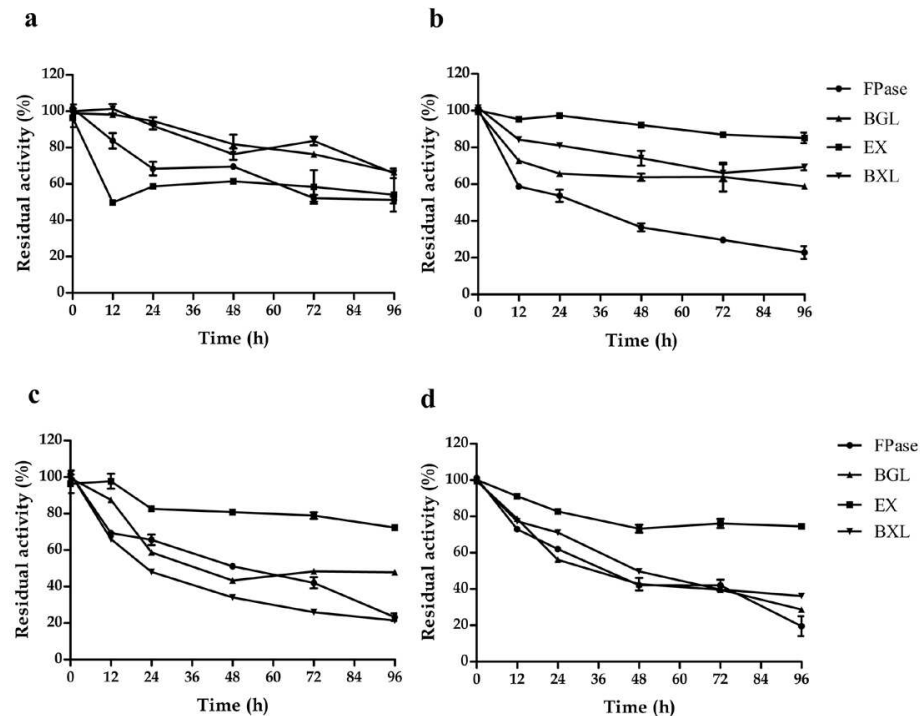

538 Figure 1. Enzymatic stability of the principal enzymes in A. niger LBM 134 enzymatic

539 cocktails. Thermostability of FPase, BGL, EX and BXL of the fungus grown on SCB

540 (a) and CB (b). pH stability of FPase, BGL, EX and BXL of the fungus grown on SCB

541 (c) and CB (d). The 100\% of each enzyme activity corresponded to the levels shown in

542 Table 2. FPase, filter paper activity; BGL, $\beta$-glucosidase; EX, endoxylanase; BXL, $\beta$ -

543 xylosidase; SCB, sugarcane bagasse; CB, cassava bagasse. 

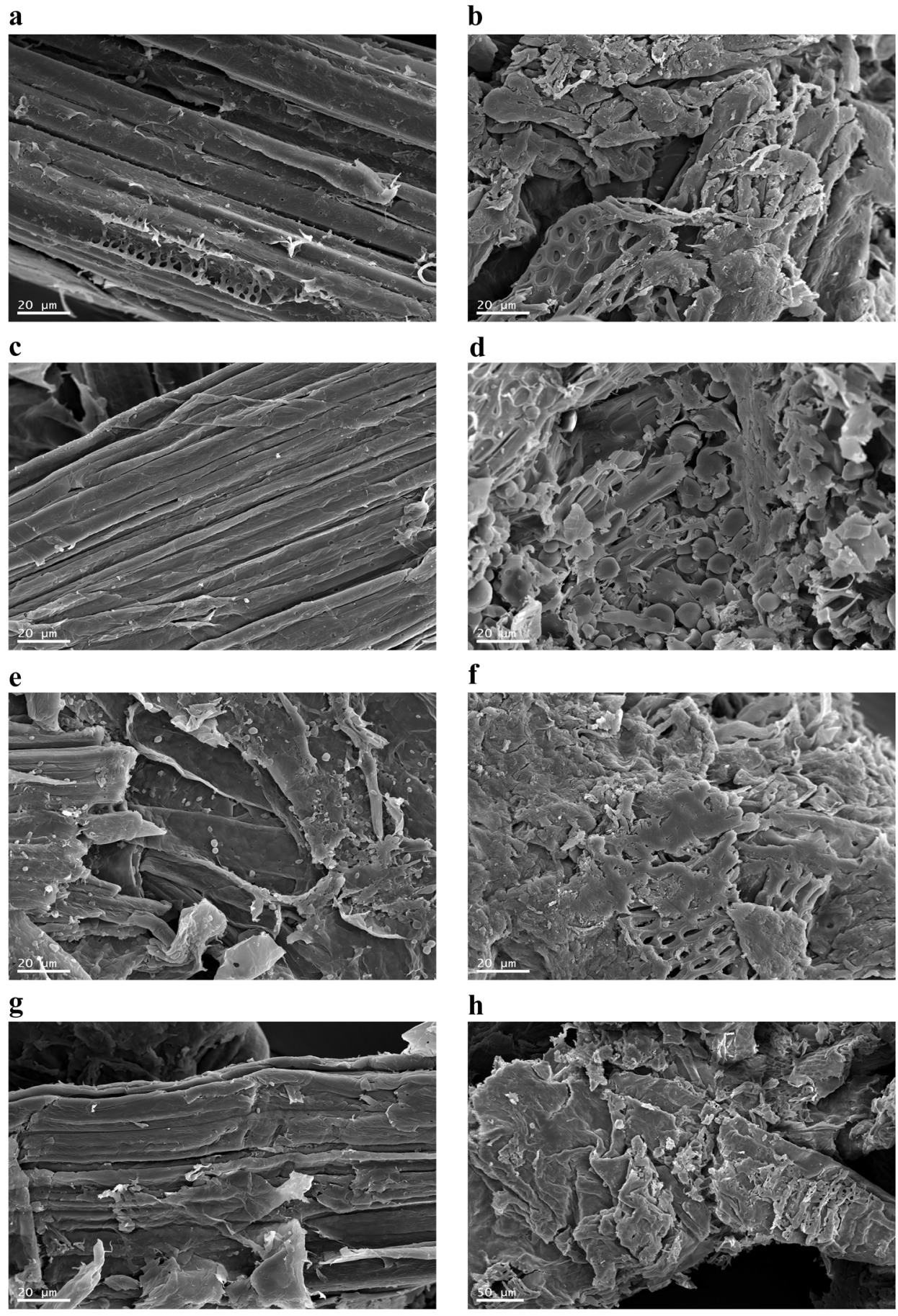

546 Figure 2. Electronic microscopic photographs of SCB and CB a) Structure of raw SCB

547 without any pretreatment. b) Structure of raw CB without any pretreatment. c) SCB

548 pretreated with alkaline solution $\mathrm{Na}(\mathrm{OH}) 0.85 \%(\mathrm{w} / \mathrm{v})$. d) $\mathrm{CB}$ pretreated with alkaline 
549 solution $\mathrm{Na}(\mathrm{OH}) 0.85 \%(\mathrm{w} / \mathrm{v})$. e) $\mathrm{SCB}$ after alkaline pretreatment and hydrolysis with

550 home-made enzymatic extract of $A$. niger LBM 134 grown on SCB. f) CB after alkaline

551 pretreatment hydrolysis with home-made enzymatic extract of $A$. niger LBM 134

552 grown on CB. g) SCB after alkaline pretreatment hydrolysis with commercial enzymes.

553 h) $\mathrm{CB}$ after alkaline pretreatment hydrolysis with commercial enzymes. SCB,

554 sugarcane bagsse; CB, cassava bagasse.

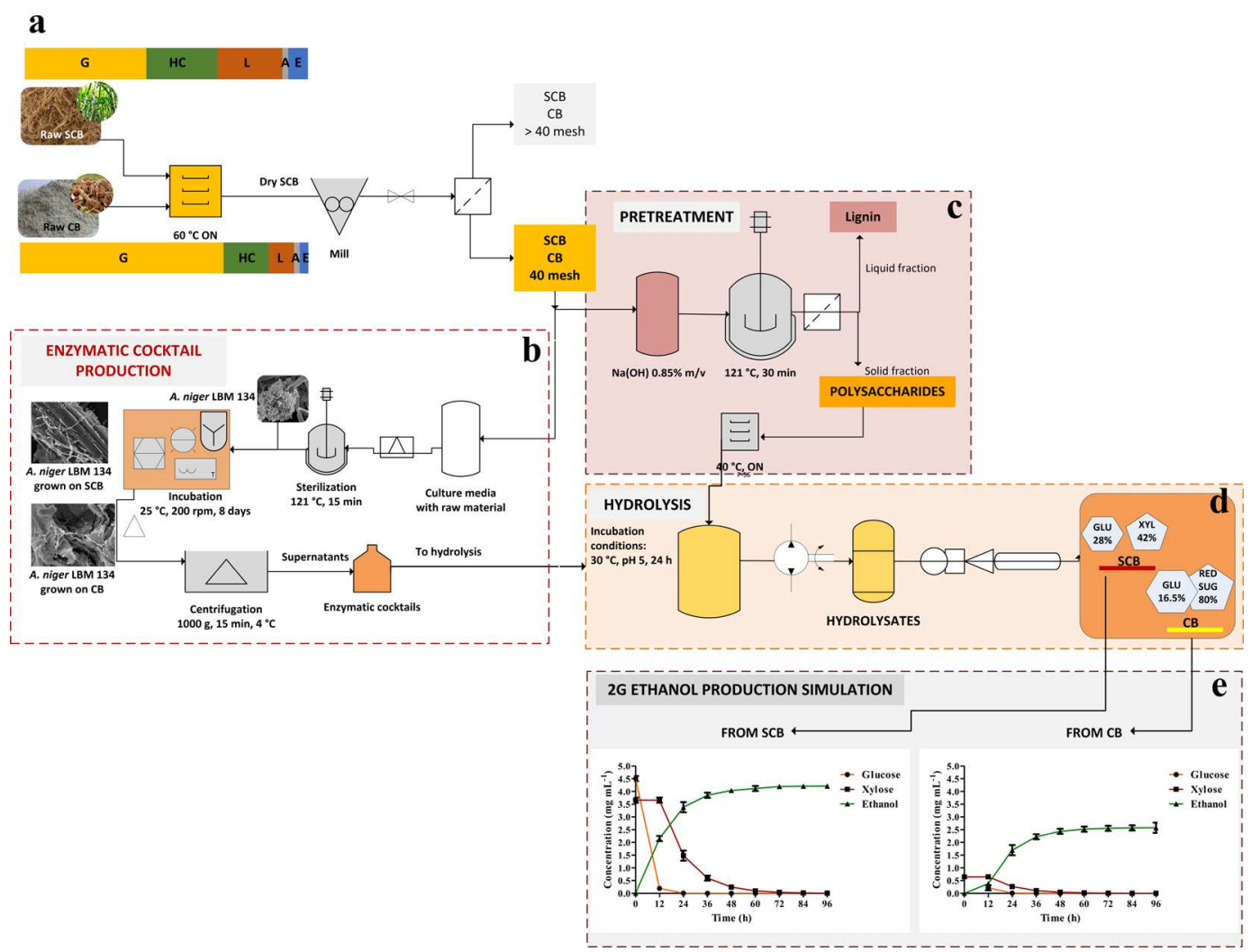

555

556 Figure 3. Bioprocess flowsheet of home-made enzymatic cocktails and bioethanol

557 production from SCB and $\mathrm{CB}$. a) Main components of raw SCB and CB: G, glucans;

558 HM, hemicelluloses; L, lignin; A, ash; E, extractives. Both bagasses were prepared for 
559 being used in the enzymatic cocktails production by $A$. niger LBM 134 (b) and in the 560 pretreatment process (c) for removing lignin; the solid fraction, rich in polysaccharides,

561 was selected for continuing the process. d) Hydrolysis of SCB and CB using the home562 made enzymatic cocktails for obtaining the hydrolysates rich in monomeric sugars, 563 GLU and XYL. e) Simulation model for bioethanol production from SCB and CB from 564 the fermentable sugars obtained in this work. SCB, sugarcane bagasse; CB, cassava 565 bagasse; GLU, glucose; XYL, xylose. 


\section{Supplementary Files}

This is a list of supplementary files associated with this preprint. Click to download.

- Supplementarymaterial.docx 